\title{
Intramolecular Hydroacylation of Unactivated Alkenes by NHC Catalysis
}

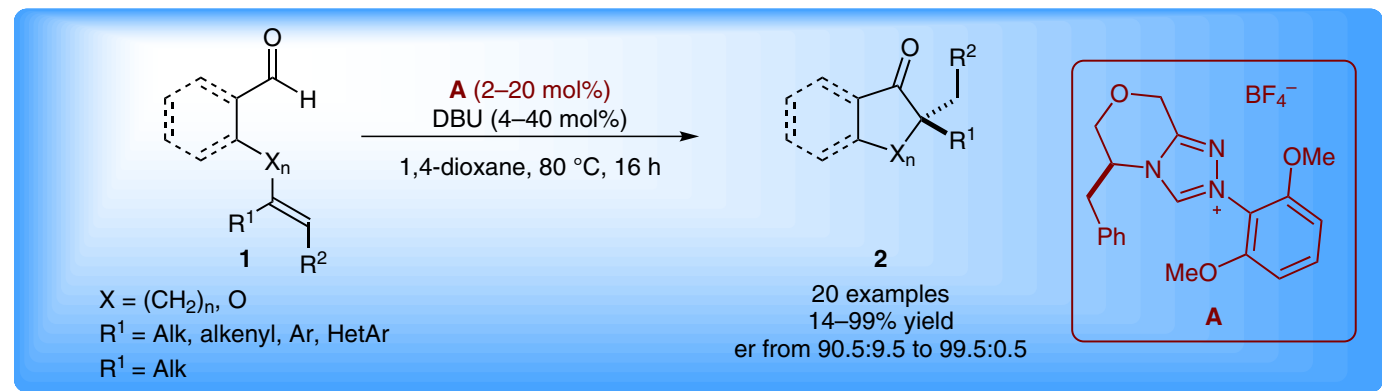

Selected examples:<smiles>C[C@]1(c2ccccc2)Cc2ccccc2C1=O</smiles>

$99 \%$ yield er $=99.5: 0.5$ (2 g scale)<smiles>C[C@]1(c2ccccc2)CCCC1=O</smiles>

$89 \%$ yield er $=99: 1$<smiles>C[C@]1(c2ccccc2)Oc2ccccc2C1=O</smiles>

$88 \%$ yield er $=92.5: 7.5$<smiles>O=C1c2ccccc2C[C@]1(Cc1ccccc1)c1ccccc1</smiles>

$77 \%$ yield er $=98.5: 1.5$<smiles>C[C@]1(c2ccccc2)CCc2ccccc2C1=O</smiles>

$92 \%$ yield er $=99: 1$<smiles>CC1Cc2ccccc2C1=O</smiles>

$71 \%$ yield<smiles>C[C@]1(/C=C/c2ccccc2)Cc2ccccc2C1=O</smiles>

$61 \%$ yield<smiles>C[C@]1(c2cccnc2)Cc2ccccc2C1=O</smiles>

$70 \%$ yield
Organo- and

Biocatalysis

Key words

hydroacylation

NHC catalysis

unactivated alkenes

quaternary

stereocenters

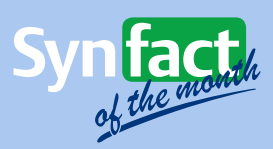

Significance: Glorius and co-workers report a highly enantioselective intramolecular N-heterocyclic carbene catalyzed hydroacylation of unactivated alkenes 1 to afford ketones $\mathbf{2}$ which bear an $\alpha$-quaternary stereocenter. By employing pre-catalyst $\mathbf{A}$, both aliphatic and aromatic aldehydes reacted smoothly to afford the desired products, by 5- or 6-exo-trig cyclization, in good to excellent yields and enantioselectivities. The scalability of the reaction was also proven by running the reaction on a two-gram scale (99\% yield, er $=99: 1)$.

SYNFACTS Contributors: Benjamin List, Gabriele Pupo Synfacts 2015, 11(6), 0659 Published online: 18.05.2015 DOI: 10.1055/s-0034-1380794; Reg-No.: B04015SF
Comment: Enantiopure ketones bearing an $\alpha$-quaternary stereocenter (2) are important motifs in biologically active molecules. The authors report an asymmetric approach to synthesize these compounds by employing simple unactivated olefins as starting materials. The methodology shows a strong functional group tolerance, proven by a 'robustness screening' and a broad substrate scope. A current limitation of the protocol is represented by the instability of products bearing an $\alpha$-tertiary stereocenter; they racemize under the basic reaction conditions. Previous mechanistic studies (Angew. Chem. Int. Ed. 2011, 50, 4983) from the same group on salicaldehyde-derived substrates suggest a protonation of the alkene from the Breslow intermediate followed by $\mathrm{C}-\mathrm{C}$ bond formation. 